\title{
Editorial
}

\section{Advances in Applied Econometrics}

\author{
Efthymios G. Tsionas, $^{1}$ William Greene, $^{2}$ and Kajal Lahiri $^{3}$ \\ ${ }^{1}$ Department of Economics, Athens University of Economics and Business, 10434 Athens, Greece \\ ${ }^{2}$ Department of Economics, Stern School of Business, New York University, New York, NY 10012, USA \\ ${ }^{3}$ Department of Economics, University at Albany, State University of New York, Albany, NY 12222, USA \\ Correspondence should be addressed to Efthymios G. Tsionas, tsionas@aueb.gr
}

Received 29 November 2011; Accepted 29 November 2011

Copyright (C) 2011 Efthymios G. Tsionas et al. This is an open access article distributed under the Creative Commons Attribution License, which permits unrestricted use, distribution, and reproduction in any medium, provided the original work is properly cited.

The purpose of this special issue is to bring together some contributions in mainly two fields: time series analysis and estimation of technical inefficiency. The fields are important in applied econometrics as they have attracted a lot of interest in recent years. In time series analysis, the analysis focuses on seasonal ARIMA models and the GQARCH-M model. In efficiency estimation a review is provided and a paper that deals with estimation of frontier models with fixed effects. Moreover, the special issue includes a paper on panel unit rooting testing and a paper on nonparametric estimation of treatment effects.

In "Some recent developments in efficiency measurement in stochastic frontier models" by S. C. Kumbhakar and E. G. Tsionas, addressed are some of the recent developments in efficiency measurement using stochastic frontier (SF) models in some selected areas. The following three issues are discussed in detail. First, estimation of SF models with input-oriented technical efficiency. Second, estimation of latent class models to address technological heterogeneity as well as heterogeneity in economic behavior. Finally, estimation of SF models using local maximum likelihood methods. Estimation of some of these models in the past was considered to be too difficult. The authors focus on the advances that have been made in recent years to estimate some of these so-called difficult models. They complement these with some developments in other areas as well. The reader is advised to consult Greene (2008) for a comprehensive review of stochastic frontier models.

G. Emvalomatis et al., in their paper "Estimation of stochastic frontier models with fixed effects through Monte Carlo maximum likelihood," propose a procedure for choosing appropriate densities for integrating the incidental parameters from the likelihood function in a general context. The densities are based on priors that are updated using information from the data and are robust for possible correlation of the group-specific constant terms with the explanatory variables. Monte Carlo's experiments are performed in the specific context of stochastic frontier models to examine and compare the sampling properties of the proposed 
estimator with those of the random effects and correlated random-effect estimators. The results suggest that the estimator is unbiased even in short panels. An application to a crosscountry panel of EU manufacturing industries is presented as well. The proposed estimator produces a distribution of efficiency scores suggesting that these industries are highly efficient, while the other estimators suggest much poorer performance.

In "Nonparametric estimation of ATE and QTE: an application of fractile graphical analysis," G. V. Montes-Rojas constructs nonparametric estimators for average and quantile treatment effects using fractile graphical analysis, under the identifying assumption that selection to treatment is based on observable characteristics. The proposed method has two steps: first, the propensity score is estimated, and, second, a blocking estimation procedure using this estimate is used to compute treatment effects. In both cases, the estimators are proved to be consistent. Monte Carlo results show a better performance than other procedures based on the propensity score. These estimators are applied to a job training dataset.

In "Estimation and properties of a time-varying GQARCH(1,1)-M model," S. Anyfantaki and A. Demos outline the issues arising from time-varying GARCH-M models and suggest to employ a Markov's chain Monte Carlo algorithm which allows the calculation of a classical estimator via the simulated EM algorithm or a simulated Bayesian solution in only $\mathrm{O}(\mathrm{T})$ computational operations, where $\mathrm{T}$ is the sample size. The theoretical dynamic properties of a time-varying GQARCH(1,1)-M are derived. They discuss them and apply the suggested Bayesian estimation to three major stock markets.

In "The CSS and the two-staged methods for parameter estimation in SARFIMA models," E. Egrioglu et al. focus on analysis of seasonal autoregressive fractionally integrated moving average (SARFIMA) models. Two methods, which are conditional sum of squares (CSS) and two-staged methods introduced by Hosking (1984), are proposed to estimate the parameters of SARFIMA models. However, no simulation study has been conducted in the literature. Therefore, it is not known how these methods behave under different parameter settings and sample sizes in SARFIMA models. The aim of this study is to show the behavior of these methods by a simulation study. According to results of the simulation, advantages and disadvantages of both methods under different parameter settings and sample sizes are discussed by comparing the root mean square error (RMSE) obtained by the CSS and twostaged methods. As a result of the comparison, it is seen that CSS method produces better results than those obtained from two-staged method.

In "Panel unit root tests by combining dependent $P$ values: a comparative study," X. Sheng and J. Yang conduct a systematic comparison of the performance of four commonly used $P$-value combination methods applied to panel unit root tests: the original Fisher test, the modified inverse normal method, Simes' test, and the modified truncated product method (TPM). The simulation results show that under cross-sectional dependence, the original Fisher test is severely oversized, but the other three tests exhibit good size properties. Sims' test is powerful when the total evidence against the joint null hypothesis is concentrated in one or very few of the tests being combined, but the modified inverse normal method and the modified TPM have good performance when evidence against the joint null is spread among more than a small fraction of the panel units. The differences are further illustrated through one empirical example on testing purchasing power parity using a panel of OECD quarterly real exchange rates.

Efthymios G. Tsionas William Greene Kajal Lahiri 


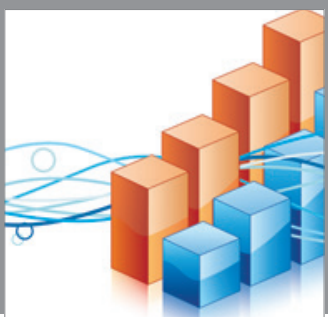

Advances in

Operations Research

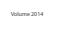

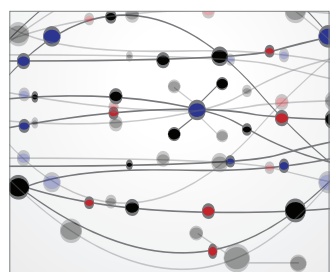

\section{The Scientific} World Journal
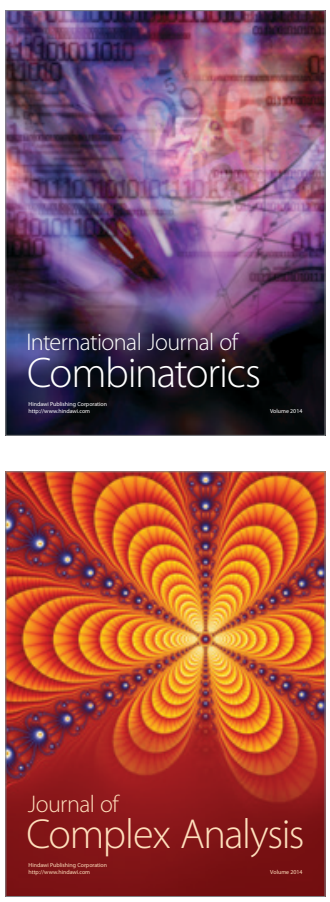

International Journal of

Mathematics and

Mathematical

Sciences
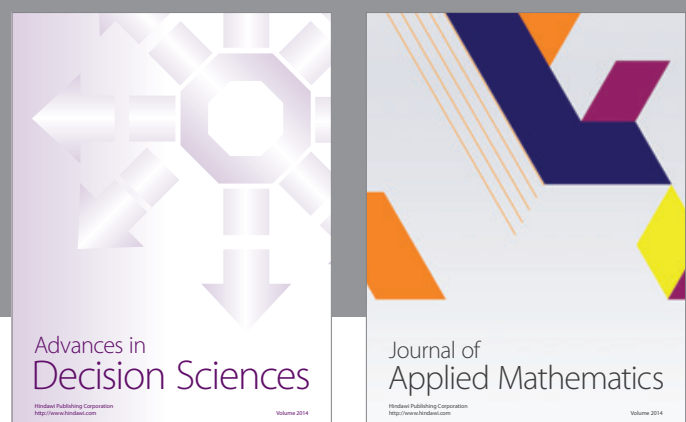

Journal of

Applied Mathematics
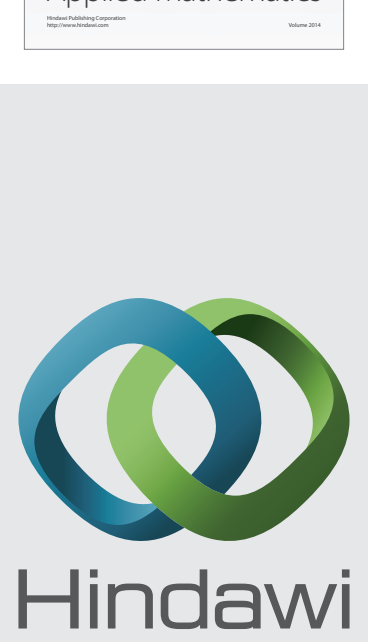

Submit your manuscripts at http://www.hindawi.com
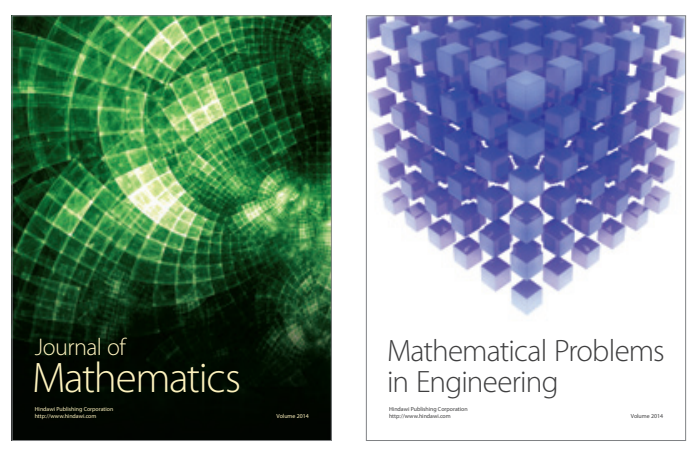

Mathematical Problems in Engineering
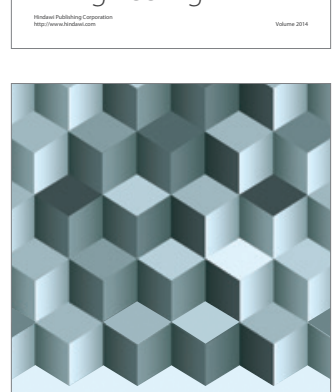

Journal of

Function Spaces
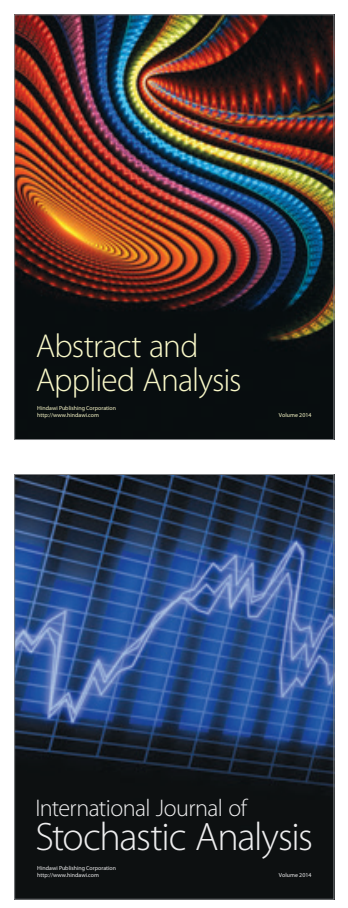

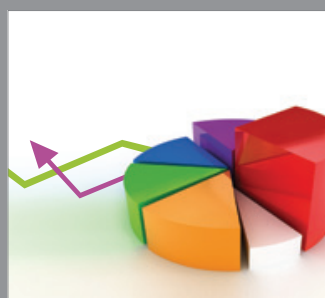

ournal of

Probability and Statistics

Promensencen
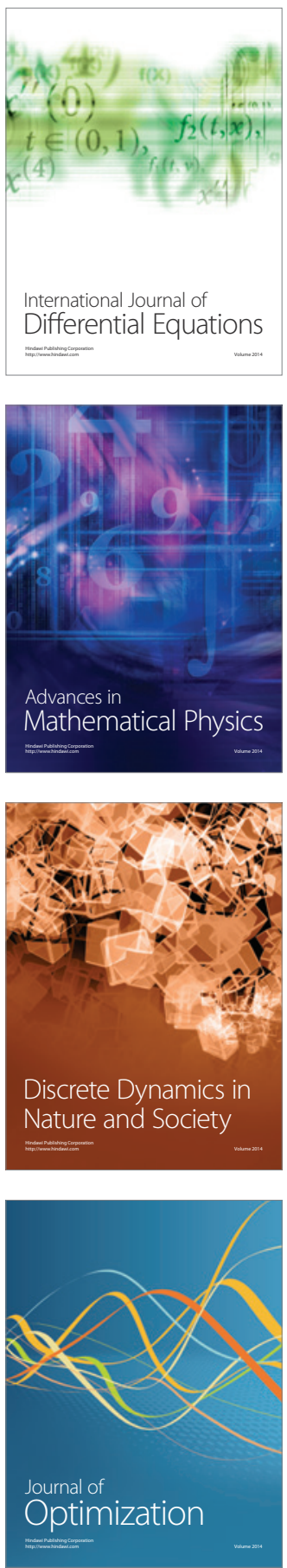